\title{
Effect of stretching through the pilates method - controlled, randomized clinical study.
}

\author{
Vanessa Stasiu', Luiz Alfredo Braun Ferreira', Martyna Athaus', Jean Pereira', Fernando Sluchensci dos Santos', \\ Patricia Stadler', Solange Dranski', Wagner Menna Pereira'
}

\begin{abstract}
Introduction: Stretching is a therapeutic technique used to increase joint range of motion and flexibility and can be used as a warm-up to prevent injury or improve muscle performance. Pilates is one of the techniques used for such benefits, improving posture, body conditioning, aiding physical and mental control, which main characteristic is resistance work and dynamic stretching. Electromyography (EMG) is the study of muscle function by checking the electrical signal coming from the muscle, as well as the study of the motor unit activity. Objective: To evaluate the electromyographic activity of the hamstring muscles using the surface EMG before and after the application of a stretching protocol through Pilates. Methods: The sample consisted of 30 healthy individuals, 15 participants from the Control Group (CG) and 15 from the Pilates Group (PG), randomly selected from which 18 were selected for analysis. Electromyography was used to evaluate hamstring muscle activity before and after the exercises. For statistical analysis was used the SPSS software version 21, for the normality of the data was used the Kolmogorov-Smirnov test, and for the comparison between the groups was used the T-Student test. The treatment program was performed in the Guairacá Integrated Clinics in Guarapuava-PR, and consisted of ten Pilates exercises during two weekly sessions of forty minute each for five weeks. Results: There was a statistically significant increase $(p=0.00)$ in the muscle activation amplitude (RMS) of the femoral and semitendinosus biceps muscles after the Pilates stretching protocol in the intervention group when compared with the control group. Conclusion: It was concluded that the Pilates Method exercise protocol directed to hamstring stretching twice a week for five weeks significantly increased muscle activation and that physical inactivity led to a reduction in this activity observed in the control group. It is recommended that further studies be developed analyzing variables not yet studied, aiming to increase scientific knowledge about the influence of stretching through Pilates on muscle performance.
\end{abstract}

Keywords: Pilates; Stretching; Electromyography; Physiotherapy.

\section{INTRODUCTION}

Stretching is a technique used to increase flexibility and maintain or improve joint range of motion which assists in preventing musculoskeletal injuries and enhances performance in activities. Lack of flexibility contributes to muscle injuries especially when it comes to hamstring muscles ${ }^{(1,2)}$. There are several ways to improve hamstring muscle flexibility such as static, dynamic stretching and proprioceptive neuromuscular facilitation (PNF). Pre-exercise static stretching is believed to reduce the risk of injury and improve performance. However, recent studies have reported that pre-exercise stretching may decrease strength production and muscle activation or have not shown a significant effect on muscle activation ${ }^{(2,3)}$. Such divergences about the potential harms or benefits that stretching techniques can generate on muscle performance prompt the study of therapeutic approaches that can support the use of stretching as an effective intervention plan in clinics, gyms or sports training centers ${ }^{(4,5)}$.

The Pilates Method, developed by Joseph Hubertus Pilates in the early 1920's, is based on the concept of contrology, which is the total conscious control of the muscular movements of the body, i.e. total mastery of the mind over the body. This technique presents six basic principles during movement without fatigue and pain: concentration, control, centralization, flow, precision and breathing. Among the objectives of the method is the strength gain, stretching and flexibility of the muscles, in which the contraction of the central muscles of the body such as the abdominal, gluteus and lumbar is maintained throughout the movement, promoting greater stability, and it is performed slowly, accurately and with few repetitions to increase muscle activation and contraction activity of this musculature, which can be observed by electromyography ${ }^{(6-8)}$.

Electromyography (EMG) is the study of muscle function by checking the electrical signal coming from the muscle, as well as the study of the motor unit activity. Some authors verify the association between amplitude and frequency of the electromyographic signal through the action pattern of the motor units. Surface EMG, used alone or in combination, can provide

Corresponding Author: Wagner Menna Pereira. Address: Rua Senira Baroni Kuster, 64, 85.065.045, Guarapuava (PR), Brazil. Telephone: (42) 9 9949-9421. E-mail: wagner.fisio@hotmail.com

Sociedade de Educação Superior Guairacá (SESG), Guarapuava (PR) - Brazil.

Funding: nothing to declare.

Submission date 21 March 2019; Acceptance date 02 May 2019; Publication date 03 December 2019 
relevant information on muscle behavior when subjected to several types of overload, angles, and execution speeds, as well as evaluating myoelectric behavior under conditions, such as temperature, environment, neuromuscular training, among others ${ }^{(10,11)}$. There are several specific applications of EMG in rehabilitation research, such as: the investigation of muscle joint stabilization strategies, the study of stretching techniques, the evaluation of muscle activity, the characteristics of muscle activity during therapeutic exercises, and the analysis of quantification of the firing rate of motor units and the identification of muscle fatigue. Given the scarcity of research evaluating the electromyographic activity of the hamstrings with EMG following a stretching protocol using the Pilates Method, this research is of great importance in contributing to science ${ }^{(12)}$. The aim of this study was to evaluate the electromyographic activity of the femoral and semitendinosus biceps muscles of the hamstring complex using surface electromyography before and after the application of a Pilates stretching protocol in healthy subjects.

\section{METHODS}

Subjects were recruited by convenience through electronic media on social networks and free will print media. The study included subjects aged between 18 and 30 years old, of both genders, non-practitioners of Pilates or any type of stretching practice, with recreational activity level only (non-athletes, practitioners of up to five hours per week of exercise) and excluded volunteers who had a history of knee osteomioarticular diseases, musculoskeletal injuries in the hamstrings, neurodegenerative, vasomotor or cardiac pathologies, infectious diseases or or who have intolerance to exercise or collection of electromyography, in addition to those that were missing in the intervention sessions. First, candidates received information about the purpose and procedure of the present study according to the National Health Council (466/2012) that regulates research with human beings. They were interviewed and filled out the inclusion and exclusion questionnaire together with their personal data. The selected ones were those that met the criteria necessary to participate in the research and then the selected subjects who agreed to participate in the research and signed the Informed Consent Form. Then the subjects were directed to a closed room with no noise which was carried out the evaluation of muscle activation of the hamstrings by surface electromyography. The study was approved by the Research Ethics Committee with number 2.201.470.

The sample consisted of 30 healthy individuals, with 12 dropouts during the study, such dropouts occurred during the interventions, in which some volunteers did not rigorously attend the meetings, needing to be excluded from the sample, resulting in 18 final analyzes. After the individual evaluation of each volunteer, the sample was divided into two groups: a Pilates Group (PG) and a Control Group (CG) at random and randomly totaling fifteen subjects in each group. The subjects from the PG were contacted by telephone to schedule the days of the week when the Pilates exercise protocol would be performed. The steps performed are in the Figure 1.

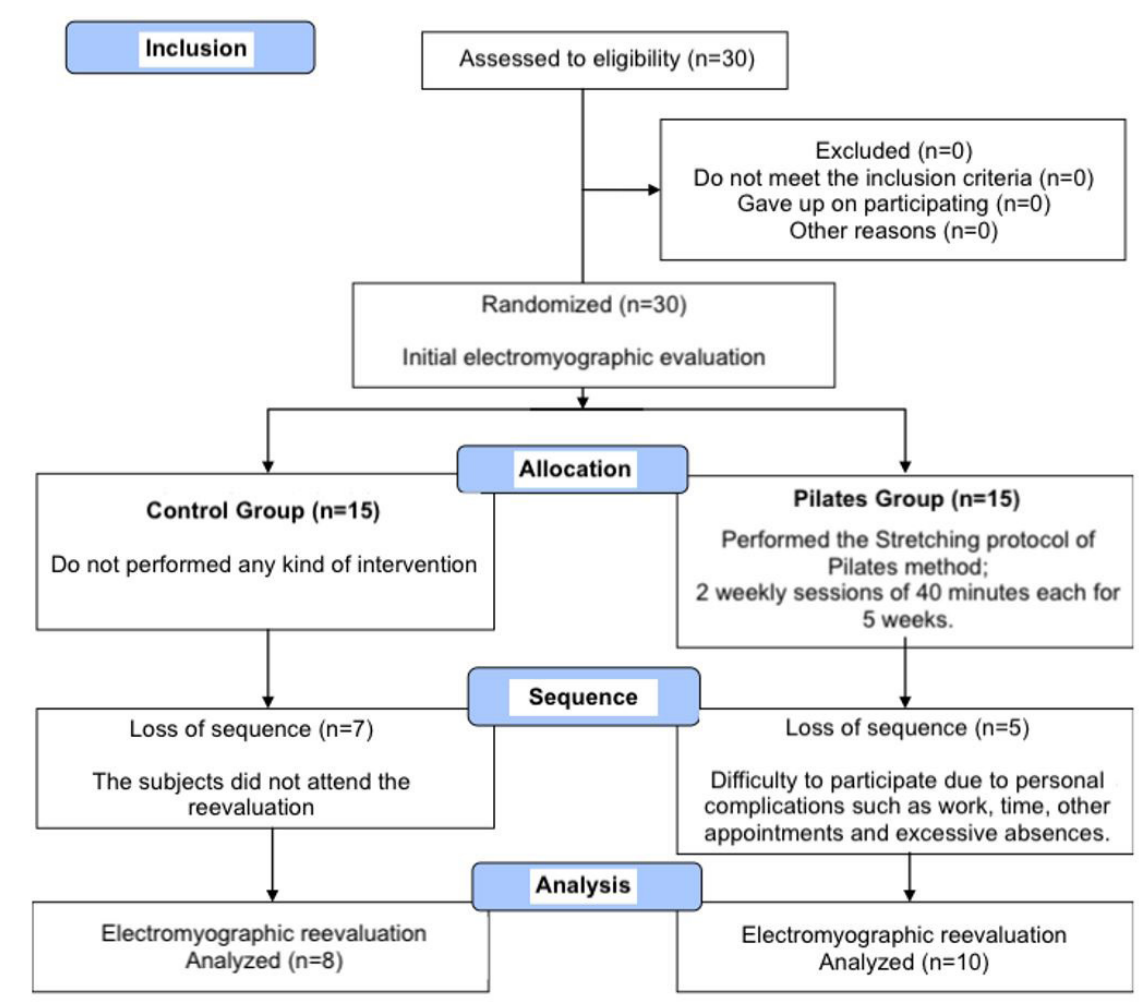

Figure 1. Flowchart of steps that were performed according to CONSORT. 
The work was carried out in the Guairacá Integrated Clinics owned by the Faculty Guairacá located in the municipality of Guarapuava-PR. After performing the Pilates method with the $P G$, the individuals who remained in the CG were invited to participate in the same exercise protocol. To obtain the electromyographic signal, the 8-channel electromyograph was used (EMG System Brasil Ltda., SJCampos (SP), Brasil), the signal being passed through a $20-500 \mathrm{~Hz}$ bandpass filter, amplified 1,000 times. Data were converted to 12-bit A/D board with $2,000 \mathrm{~Hz}$ sampling frequency for each channel and an input range of $5 \mathrm{mV}$. Active type bipolar surface electrodes were used, coupled to a 20 -fold differential preamplifier, with a distance of $20 \mathrm{~mm}$ between them, attached to the skin by Miotec ${ }^{\circledR}$ adhesive electrodes. Muscle electrical activity was measured using Root Mean Square (RMS) values (Figure 2: a). Following the SENIAM (Surface Electromyography for Noninvasive Assessment Muscles) criteria for electrode placement, the femoral biceps muscle was positioned at $50 \%$ distance between the ischial tuberosity and the lateral epicondyle of tibia while for the semitendinosus muscle it was positioned $50 \%$ of the distance between the ischial tuberosity and the lateral epicondyle of tibia (Figure 2: b). The reference electrode was positioned at the bony end of the styloid process of the ulna of the contralateral limb. All subjects underwent skin preparation with trichotomy and cleaning with $70 \%$ alcohol to reduce impedance ${ }^{(13,14)}$.

The electromyographic evaluation of muscle activation was performed through maximal voluntary isometric contraction (MVIC), using a force cell (Figure 2: c), a strain gauge usually in the newtons force unit, in which the force is electronically captured, amplified and recorded simultaneously with the EMG that was conducted to a general monitor for recording, with the load cell and electrodes attached to the dominant member ${ }^{(15,16)}$. The subject's initial position was seated with 900 of hip and knee flexion (Figure 2: d), starting with a knee flexion with maximum force keeping the contraction isometric for 60 seconds in which the muscle activation data were collected using the RMS values before and after the stretching exercises with the Pilates method. The reevaluation was performed one week after the last intervention with the same evaluation criteria.

According to previous studies using the Pilates method, interventions were performed twice a week over a period of five weeks. The final position of the stretch was until there was a slight tightening sensation of moderate intensity in the hamstrings, but without exceeding the pain threshold, and the rest time between each exercise was 30 seconds ${ }^{(17-19)}$. Prior to the beginning of the exercise program, all participants received a basic introduction to Pilates exercises correctly and were trained on how to activate the core muscles, involving isometric contraction of the transverse abdominis, the pelvic floor, and the multifidus while exhaling air and performing movement during diaphragmatic breathing ${ }^{(20)}$. The protocol consisted of ten Pilates exercises for hamstring muscle stretching, which was elaborated according to exercises already published in the scientific literature ${ }^{(8,9,20)}$, being static and mostly dynamic stretching following the Pilates principles ${ }^{(6)}$. The elaborated exercise protocol is shown in figures 3 and 4 .

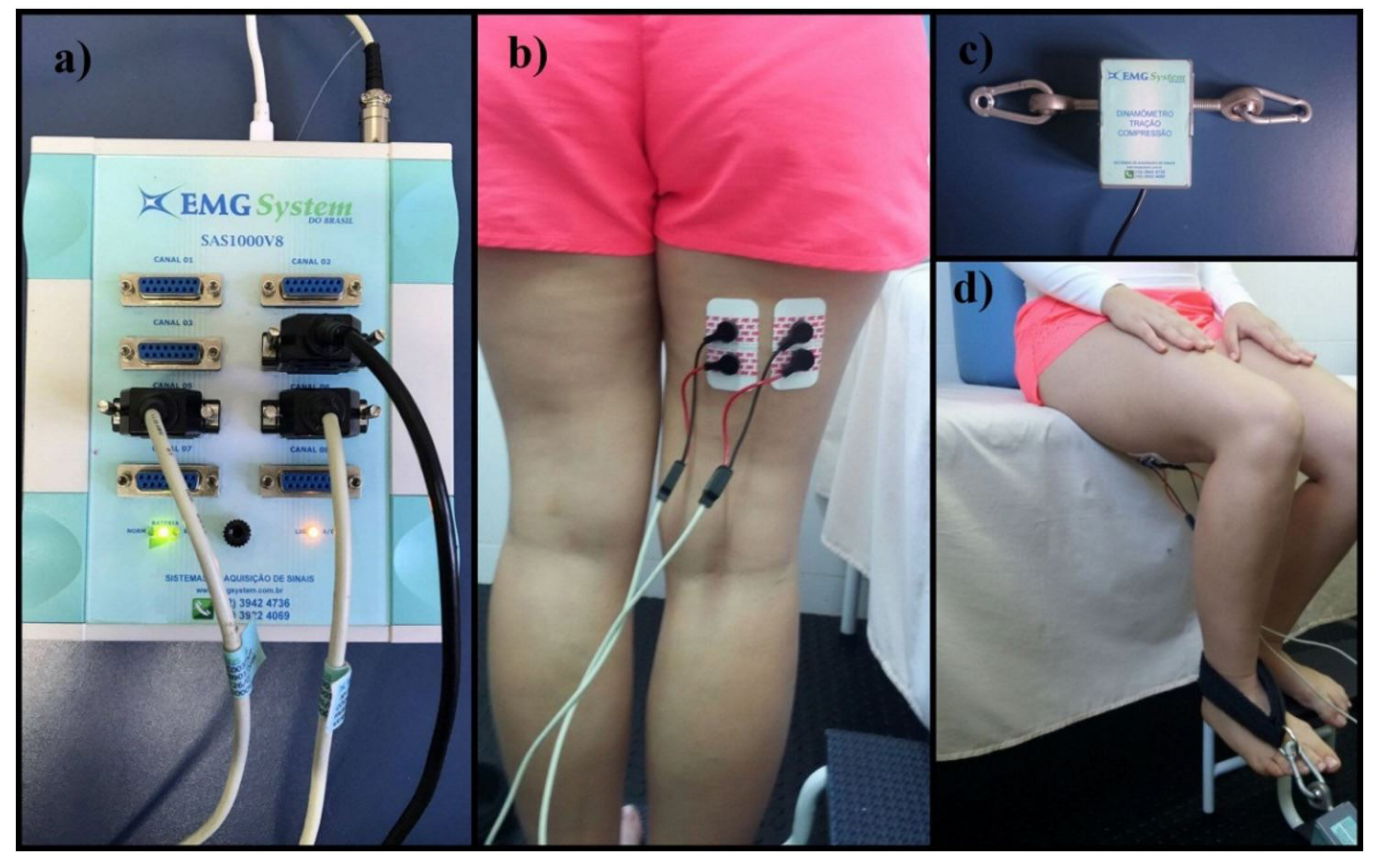

Figure 2. Obtaining the electromyographic signal. Note: a) 8-channel electromyograph (EMG System Brasil Ltda.); b) Electrode Positioning; c) Force Cell; d) Subject position. 


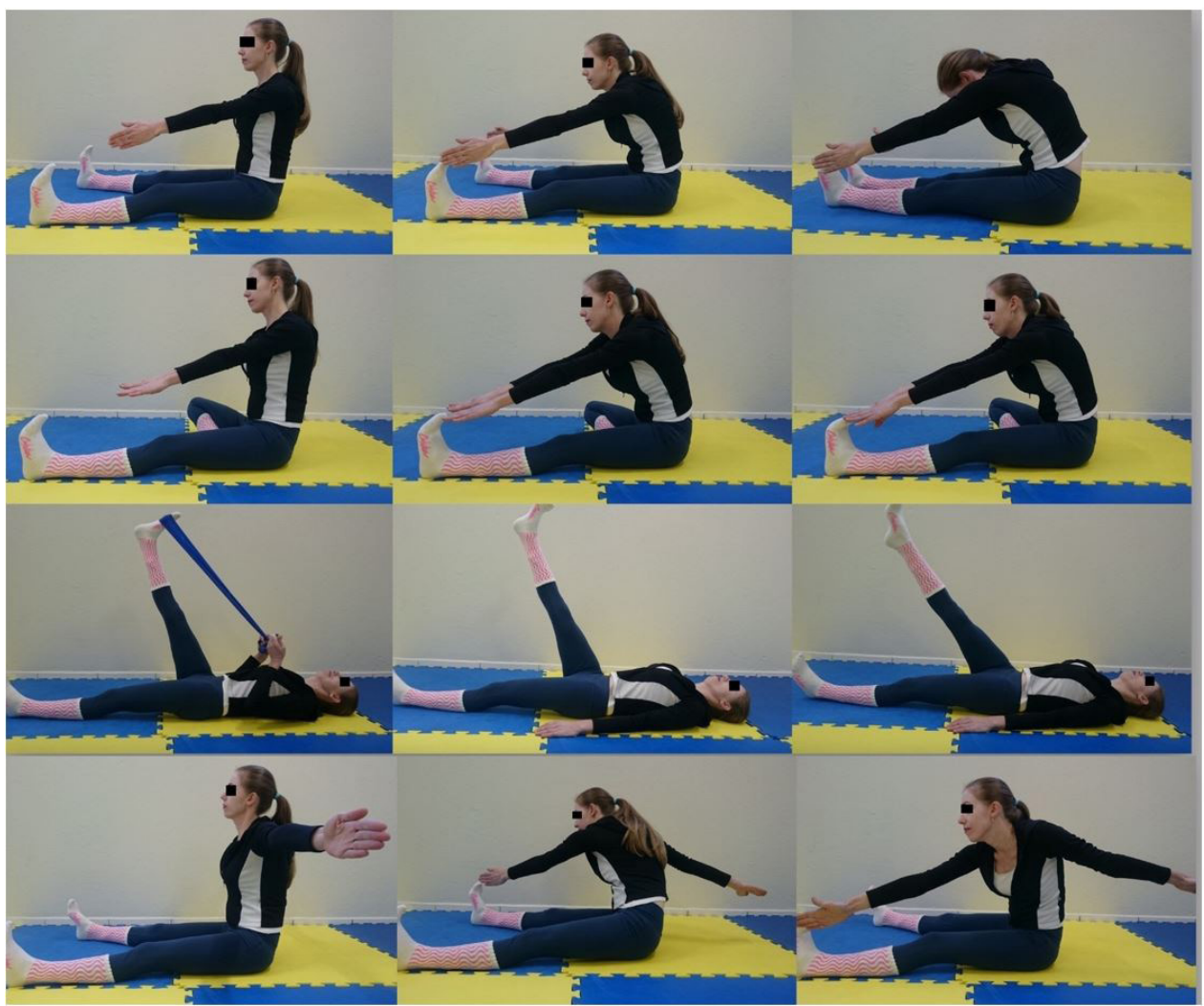

Figure 3. Exercises protocol. Note: 1. Spine stretch; 2. Hamstring stretch; 3. Hamstring stretch (variation); 4. Leg series supine: circles; 5 . The Saw.

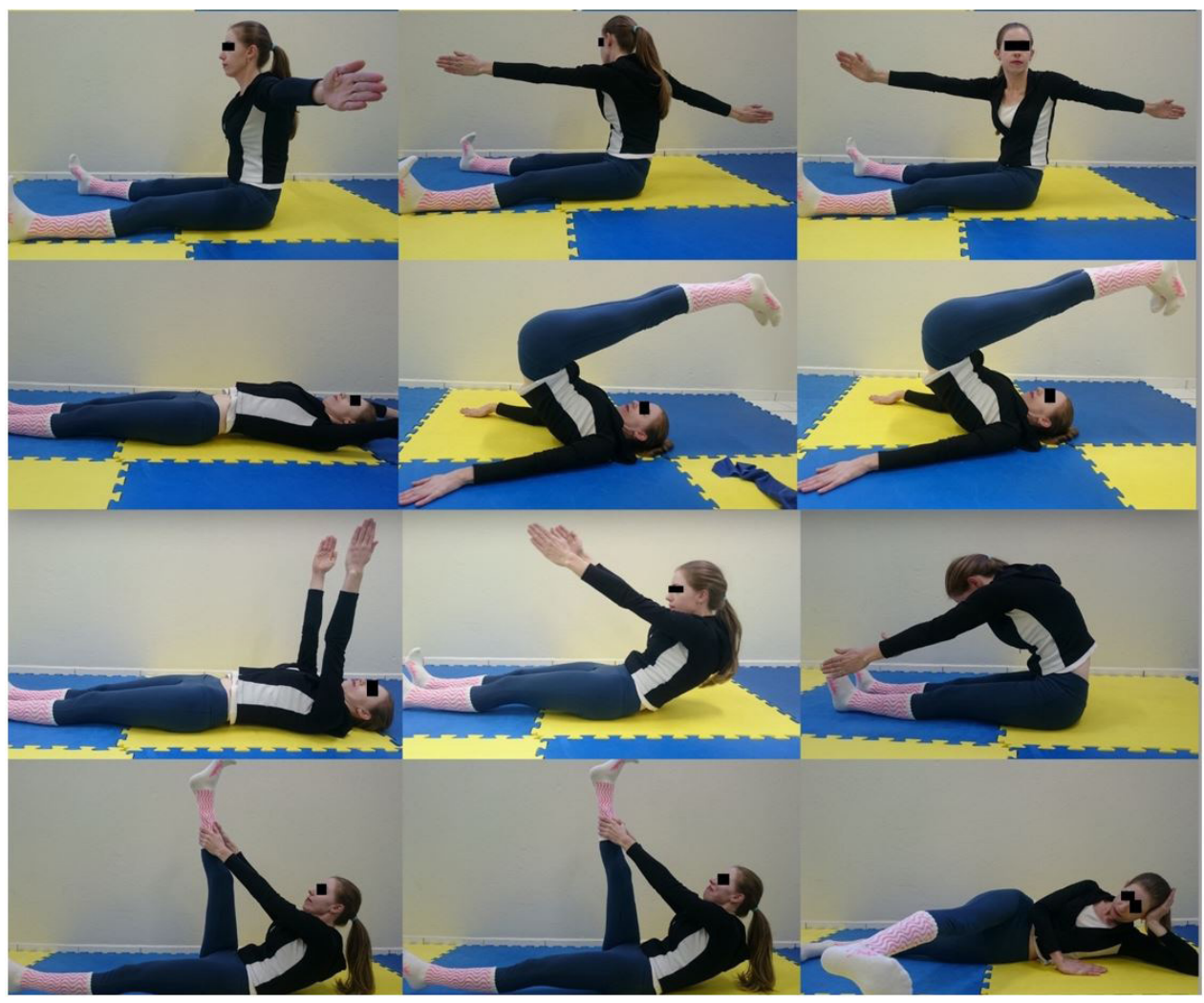

Figure 4. Continuation of the Exercises protocol. Note: 6. Spine Twist; 7. Roll-over; 8. Roll-up; 9. Single Sraight; 10. Leg Strech Side Kick (Front and Back). 


\section{STATISTICAL ANALYSIS}

Statistical analysis was performed using SPSS version 21 software for Windows. To test data normality, the Kolmogorov-Smirnov test was performed, which showed normal distribution of data. To the comparison between the groups, it was used the T-Student test that demonstrated a statistically significant increase in the semitendinosus RMS $(p=0.00)$.

Table 1. Anthropometric characteristics of subjects.

\begin{tabular}{cccc}
\hline Variables & Control group & Pilates group & $\begin{array}{c}* \text { Statistic } \\
(\mathbf{p}<0.05)\end{array}$ \\
\hline Subjects & 8 & 10 & \\
Male/Female & $01 / 07$ & $0 / 10$ & 0.860 \\
Age (years) & $24.6(3.25)$ & $24.3(4.22)$ & 0.368 \\
Weight (Kg) & $60.0(12.09)$ & $64.8(10.09)$ & 0.642 \\
Height (m) & $1.62(5.50)$ & $1.63(4.36)$ & 0.321 \\
BMI & $22.6(3.41)$ & $24.53(4.11)$ &
\end{tabular}

Note: *Unpaired T-Student test $(\mathrm{p}<0.05)$ was performed to compare anthropometric variables between groups.

\section{RMS DO MÚSCULO SEMITENDINOSO}

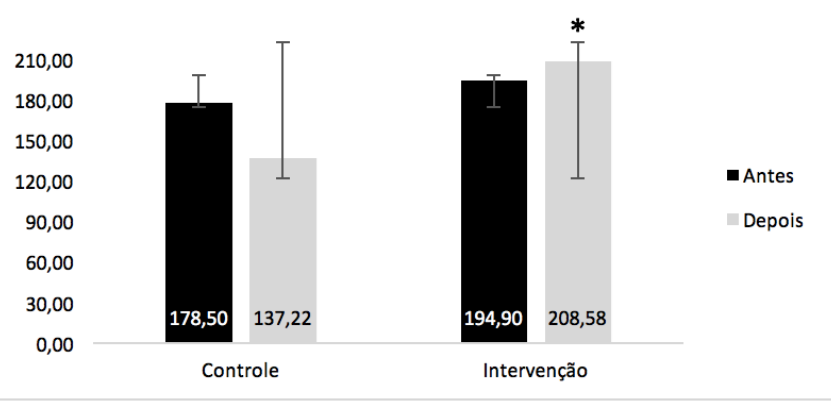

Figure 5. Electromyographic activity of semitendinous muscle. Note: *Significant difference in the increase in muscle activation (RMS) of the semitendinosus muscle after stretching with the Pilates method $(p=0.002)$ compared to the control group.

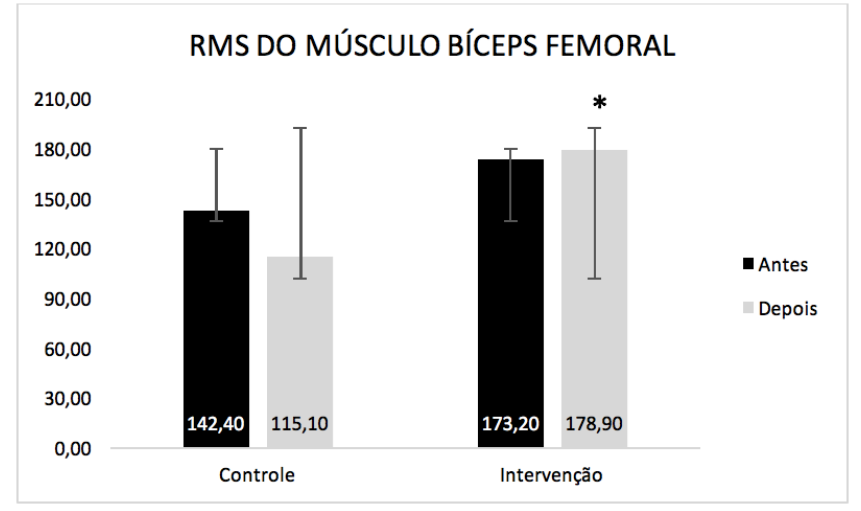

Figure 6. Electromyographic activity of femoral biceps muscle. Note: *Significant difference in increased muscle activation (RMS) of the biceps femoris muscle after stretching with the Pilates method ( $p<0.05)$.

\section{RESULTS}

After eliminating some missing volunteers during the interventions, eighteen individuals who met the eligibility criteria remained. Anthropometric characteristics are reported in Table 1.

Shown below is the electromyographic activity (RMS) of the semitendinosus muscle before and after the interventions of the control and intervention groups, as shown in Figure 5 . Note that there was a decrease in RMS in the control group ( $p=0.093$ ) and an increase in RMS in the intervention group $(p=0.381)$, but these differences were not significant. In the intergroup comparison, the intervention group obtained a statistically significant increase compared to the control group $(p=0.002)$.

Figure 6 shows the activation of the femoral biceps muscle before and after interventions by the Pilates group and the control group. There was a decrease in muscle activation in the control group ( $p=0.095$ ) and an increase in the intervention group $(p=0.811)$, but these differences were not statistically significant. In the intergroup comparison, the intervention group obtained significant difference compared to the control group (0.007).

\section{DISCUSSION}

The results of the present study indicated that there was a statistically significant increase in muscle activation of the biceps femoral and semitendinosus muscles following a Pilates stretching protocol in the intervention group when compared with the control group. The sample analyzed consisted of 18 individuals, 17 women and only 1 man, who demonstrated homogeneity, having similar anthropometric characteristics, such as an ideal body mass index and a low standard deviation, which strengthens the findings of the present research. The results were also significant probably by the sum of the different forms of stretching (active, passive, static, dynamic) contained and provided by the Pilates method.

The Pilates method consists of exercises whose main characteristic is resistance work and dynamic stretching ${ }^{(21)}$. Dynamic stretching tends to increase core temperature which can increase nerve conduction velocity, muscle adhesion, enzyme cycle, accelerating energy production and consequently generating increased muscle activity, while in static stretching, core activity can decrease, impair muscle performance and reduce muscle activation ${ }^{(22)}$. Such reduction may be due to the Golgi tendon reflex, which generates an inhibitory reflex on the muscle when being stretched promoting relaxation. It is also possible that static stretching may cause an increase in viscoelastic properties of the muscle tendon unit after stretching, which is thought to alter the force-relaxation property within a muscle, thereby decreasing its working capacity ${ }^{(23)}$. The literature reports the indication of increased EMG activity after dynamic stretching compared to static stretching, which is consistent with the present study that also showed a statistically significant increase in muscle activation $^{(23)}$. 
In agreement with the present study, the study ${ }^{(3)}$ evaluated 18 young athletes who were randomly divided into passive and dynamic stretching groups by 12 interventions and concluded that flexibility improved significantly in both groups and that electromyography showed a large difference, while the static group showed a decrease in the electrical signal in the acute phase, and dynamic stretching presented a clear increase in the chronic phase compared to the initial evaluation. This result may be due to the number of interventions that significantly influenced as in the present study. Although the sample is composed of young athletes and the present study by non-physical active women, the results were similar agreeing that the dynamic stretching promotes an increase in the muscular activation in different muscular conditions ${ }^{(3)}$. In order to investigate the effects of passive static stretching of the antagonist during an interconnected rest period on repetition performance and muscle activation of the dorsal, biceps brachii and pectoralis, ten trained men participated in this study. The paddling exercise was performed using two protocols, one with repetitions until failure with rest interval, and another with static stretching of the antagonist (Pectoral) during the interval for 40 seconds $^{(23)}$. They concluded that the antagonistic passive static stretching adopted during the rest period had a significant increase in the number of repetitions, an improvement in the strength and an increase in the activation of the agonist muscles (Latissimus dorsi and Biceps Brachii) in an acute manner compared with the group of interval with passive recovery. Thus, antagonist stretching may induce an increase in elastic energy storage, agonist activation, reduction of antagonist coactivation, as well as an increase in the number of repetitions ${ }^{(24-26)}$.

In the current study, it was obtained an increase in muscle activation due to the sum of several dynamic agonist stretches, in contrast, in the studies mentioned above, there was an increase in muscle activation through static stretching of the antagonist. Agonist static stretching before exercise may lead to reduced strength, but during the rest interval antagonist static stretching increased agonist muscle activation and could be used to improve muscle performance ${ }^{(25,27)}$. There is a study involving 14 sedentary young adults that collected the electromyographic signal (EMG) of the biceps femoris muscle before and after passive hamstring stretching with 3 sets of 60 seconds. As a result, the acute effects of passive stretching did not significantly influence the muscle activation pattern of the femoral biceps ${ }^{(2)}$. They explain that the divergent findings may be related to several factors such as the characteristics of the evaluated samples, gender, age, intensity and duration of stretching ${ }^{(4)}$.

Ballistic stretching, static stretching, and proprioceptive neuromuscular facilitation (PNF) as well as the Pilates method are widely used to improve hamstring muscle flexibility. They performed the PNF technique for hamstring lengthening with antagonist muscle contraction and obtained a statistically significant increase in muscle activation ${ }^{(5)}$. In the present study, some Pilates hamstring stretching exercises were also performed with a joint antagonist muscle contraction, which may have influenced an increase in muscle activation, obtaining a similar result. Whereas antagonist muscle co-activations are common to prevent joint overload during sports $^{(25)}$. However, they conducted a survey of 60 volunteers who were divided into 4 groups: control, warm-up, stretching, warm-up associated with stretching. Warm-up was performed on a stationary bike for 5 minutes and the passive and static stretching of the quadriceps and hamstring muscles (three sets of 30 seconds for each muscle) ${ }^{(14)}$. Results showed that there was no significant change in activation amplitude in any of the intervention groups when comparing RMS values. This may be because the time is 30 seconds, being less than 60 seconds, longer stretching durations (eg, $\geq 60 \mathrm{~s}$ ) are likely to cause a decrease in muscle performance. On the other hand, passive and static stretching, used alone or associated with warming, promoted a reduction in hamstring muscle latency time (MLT), which is considered the time interval between the onset of angular variation and the timing of recording effective muscle activity $^{(22)}$. In the present research, the MLT was not evaluated, but it is possible to relate it, because through stretching and along with warming promoted a reduction, i.e., the muscle activation started more quickly. Regarding the Control Group, the results showed a decrease in muscle activation that may be justified by the fact that the lack of mechanoreceptor stimuli, the lack of stretching or physical inactivity, is directly related to the decrease in muscle work.

The main limitations of the present study are the lack of studies related to the use of Pilates Method as a form of hamstring stretching evaluating through electromyography and the small sample size due to the difficulty of the volunteers to remain in the research due to personal complications or schedule flexibility.

\section{CONCLUSION}

It was concluded that the Pilates Method exercise protocol directed to hamstring stretching twice a week for five weeks significantly increased muscle activation. It is recommended that further studies be developed with a similar therapeutic approach analyzing the influence of different stretching types and times through the Pilates Method on the muscle strength and activity of agonists and antagonists, as well as comparison between genders in a larger sample.

\section{AUTHORS' CONTRIBUTION}

VS and MA: data collection; LABF: methodological planning and study design; JP: article writing and adjustment of theoretical corrections; FSS and OS: statistical analysis and article writing; SD: intellectual and critical review of the manuscript; WMP: drawing, writing and correction of the manuscript. All authors read and approved the final manuscript.

\section{CONFLICT OF INTEREST}

nothing to declare. 


\section{REFERENCES}

1. Cristóbal RV, Minãrro PAL, Cárceles FA, Ross FE. Efectos del método Pilates sobre la extensibilidad isquiosural, la inclinación pélvica y la flexión del tronco. Nutrición hospitalaria: Organo oficial de la Sociedad española de nutrición parenteral y enteral. 2015;32(5):1967-86.

2. Bley AS, Nardi OS, Marchetti PH. Alongamento passivo agudo não afeta a atividade muscular máxima dos isquiotibiais. Motricidade. 2012;8(4):80-86.

3. Gonçalves DL, Pavão TS, Dohnert MB. Acute and chronic effects of a static and dynamic stretching program in the performance of young soccer athletes. Rev. Bras. de Medicina do Esporte. 2013;19(4):241-246.

4. Chatzopoulos D, Galazoulas C, Patikas K, Kotzamanidis C. Acute effects of static and dynamic stretching on balance, agility, reaction time and movement time. Journal of sports science \& medicine. 2014;13(2):403.

5. Mendonça M, Araújo MG, Fonseca C, Lima M, Mèlo L, Rocha S, Guerino M, Lima AP, Silva KM. Transcranial magnetic stimulation associated withmanual therapy in patients with knee osteoarthrits: a randomized controlled clinical trial protocol. Manual Therapy, Posturology \& Rehabilitation Journal. 2018;16(608):1-4.

6. Mostagi FQRC, Dias JM, Pereira LM, Obara K, Mazuquin B, Silva MF et al. Pilates versus general exercise effectiveness on pain and functionality in non-specific chronic low back pain subjects. Journal of bodywork and movement therapies. 2015;19(4):636-645.

7. Kloubec JA. Pilates for improvement of muscle endurance, flexibility, balance, and posture. The Journal of Strength \& Conditioning Research. 2010;24(3):661-667.

8. Trevisol FC, Da Silva S. Aula inicial de pilates promove efeito agudo na flexibilidade da musculatura isquiotibial. RBPFEX-Revista Brasileira de Prescrição e Fisiologia do Exercício, 2009;3(14):161-170.

9. Teles FS, Pereira MC, Júnior VDAR, Carmo JCD, Andrade MMD. Electromyographic parameters in fatiguing exercises performed with different types of resistance. Fisioterapia \& Pesquisa. 2016;23(3):257-262.

10. Oliveira DCSD, Santos PAMD, Rezende LD, Guimarães EA, Chacur EP. Electromyographic analysis of lower limb Muscles in proprioceptive exercises performed With eyes open and closed. Rer. Bras. de Medicina do Esporte. 2012;18(4):261-266.

11. Ferreira LAB, Pereira WM, Vieira FF, Rossi LP. Ativação eletromiográfica dos músculos da perna em exercícios proprioceptivos na reabilitação de tornozelo: Uma revisão bibliográfica. In: Anais XI Encontro Latino Americano de Iniciação Científica e VII Encontro Latino-Americano de Pós-Graduação-Universidade do Vale do Paraíba. São José dos Campos, Brasil. 2007, 1119-1122.

12. Hermes JH, Freriks B, Klug CD, Ray G. Development of recommendations for SEMG sensors and sensor placement procedures. Journal of electromyography and Kinesiology. 2000;10(5):361-374.

13. Nogueira JFDS, Lins VADA, Souza AVC. Brasileiro JS. Efeitos do aquecimento e do alongamento na resposta neuromuscular dos isquiotibiais. Ver. Bras. de Medicina do Esporte. 2014;20(4):262-266.
14. Reis DFDFS, Pereira GB, Sousa NMF, Tibana RA, Silva MF, Araujo $M$ et al. Acute effects of proprioceptive neuromuscular facilitation and static stretching on maximal voluntary contraction and muscle electromyographical activity in indoor soccer players. Clinical physiology and functional imaging.2013;33(6):418-422.

15. Barbosa AM, Camassuti PADS, Tamanini G, Marcolino AM, Barbosa RI, Fonseca MDCR. Reliability and validity of a load cell device for hand grip strength assessment. Fisioterapia \& Pesquisa. 2015;22(4):378-385.

16. Wajswelner $\mathrm{H}$, Metcalf $B$, Bennell K. Clinical Pilates versus general exercise for chronic low back pain: randomized trial. Medicine \& Science in Sports \& Exercise. 2012;44(7):1197-2005.

17. Díaz DC, Amat AM, Cruz MJDLT, Casuso RA, Guevara NMLD, Contreras FH. Effects of a six-week Pilates intervention on balance and fear of falling in women aged over 65 with chronic low-back pain: A randomized controlled trial. Maturitas. 2015;82(4):371-376.

18. Lax AB, Cristóbal RV, Antúnez LE, Miñarro PAL. Efecto de un programa de estiramiento de la musculatura isquiosural sobre la extensibilidad isquiosural en escolares adolescentes: influencia de la distribución semanal de las sesiones. Nutrición Hospitalaria. 2015;32(3):1241-1245.

19. Valenza MC, Torres JR, Martos IC, Pelegrina AD, Ferrándiz MEA, Caballero $C Y$. Results of a Pilates exercise program in patients with chronic non-specific low back pain: A randomized controlled trial. Clinical rehabilitation. 2016;31(6):753-760.

20. Justino BS e Pereira WM. Efeito do método Pilates em mulheres gestantesEstudo Clínico Controlado e Randomizado. Publication UEPG: Ciências Biológicas e da Saúde. 2016;22(1):55-62.

21. Behm DG, Blazevich AJ, Kay AD. Acute effects of muscle stretching on physical performance, range of motion, and injury incidence in healthy active individuals: a systematic review. Applied physiology, nutrition, and metabolism. 2016;41(1):1-11.

22. Amiri-Khorasani M, Osman N, Yusof A. Electromyography assessments of the vastus medialis muscle during soccer instep kicking between dynamic and static stretching. Journal of Human Kinetics. 2010;24(1):35-42.

23. Miranda H, Maia MDF, Paz GA, Costa PB. Acute effects of antagonist static stretching in the inter-set rest period on repetition performance and muscle activation. Research in Sports Medicine. 2015;23(1):37-50.

24. Serefoglu A, Sekir U, Gür H, Akova B. Effects of Static and Dynamic Stretching on the Isokinetic Peak Torques and Electromyographic Activities of the Antagonist Muscles. Journal of sports science \& medicine. 2017;16(1):6.

25. Paz GA, Maia MF, Lima VP, Oliveira CG, Bezerra E, Simão R et al. Maximal exercise performance and electromyography responses after antagonist neuromuscular proprioceptive facilitation: A pilot study. Journal of Exercise Physiology Online. 2012;15(6):60-67.

26. Ruan M, Zhang Q, Wu X. Acute Effects of Static Stretching of Hamstring on Performance and Anterior Cruciate Ligament Injury Risk During Stop-Jump and Cutting Tasks in Female Athletes. Journal of strength and conditioning research. 2017;31(5):1241. 